\title{
O OBJETO DE ESTUDO DA CIÊNCIA DA INFORMAÇÃO: A MORTE DO INDIVÍDUO
}

\author{
Luiz Fernando de Barros Campos \\ Ludmila Salomão Venâncio
}

\begin{abstract}
Resumo
Argumenta-se que o campo da Ciência da Informação encontrou sua expressão máxima do individualismo quando adotou uma orientação cognitivista, parcialmente como desdobramento da valorização do físico e sistêmico em seus anos fundadores. Procura-se mostrar, por meio de uma exposição epistemológica de metateorias, que as tendências atuais apontam para a premência de uma abordagem holística e interdisciplinar, que efetivamente integre o material e o social e incorpore múltiplas dimensões, como a sociológica, situacional, política, filosófica, lingüística, emocional, cultural, histórica e epistemológica. Assim, destaca-se a emergência do neopragmatismo, dos novos estudos da linguagem e da mente, do construtivismo e suas repercussões no campo. A análise de domínio é considerada exemplar do argumento defendido, e por isso são expostos seus fundamentos. Os conceitos e a metodologia de Foucault são admitidos como um meio efetivo de constituição de objetos de estudos integrados. Ainda, no escopo delimitado, reconhecendo a tensão em que a virtualidade coloca a materialidade documental, efetuam-se alguns comentários sobre suas implicações.
\end{abstract}

\section{Palavras-Chave}

Objeto de Estudo; Cognitivismo, Neopragmatismo; Linguagem, Construtivismo; Análise de Domínio

\section{INTRODUÇÃO}

O texto "A morte do Autor" de Barthes provocou muita polêmica quando publicado em 1968 (BARTHES, 2004). Ele defendia que a linguagem conhecia um sujeito, não um "eu" particular, que a concepção de autor era uma construção moderna e que um discurso era sempre uma escritura múl- 
tipla, a ser desvendada pelo leitor. Foucault (1992), em "O que é o Autor?", instituiu uma função-autor, que pode ser caracterizada como: (a) ligada ao sistema jurídico e institucional que determina o universo do discurso (na linha dos direitos autorais); (b) dependente do tipo do discurso e da época histórica (os gregos não cobravam a autoria de seus rapsodos); (c) não espontânea como a atribuição de um discurso a um indivíduo, mas antes a complexa construção de um ser racional (uma identidade) a que chamamos autor; e (d) não identificada simplesmente com um indivíduo real, já que os vários "eus" presentes no discurso sinalizam diferentes posições-sujeitos.

É claro que não se deve tomar literalmente uma proposição como a eliminação da autoria dos discursos. Um crítico de Foucault argumentou (FOUCAULT, 1992) que não se trata de negar o homem ou o autor, mas de substituir um sujeito individual por um sujeito coletivo ou transindividual. Mas talvez o ponto principal resida em uma certa inversão da análise: Foucault (1992) respondeu a seu crítico afirmando que o "apagar" do autor era em proveito das formas próprias aos discursos, permitindo descobrir o jogo da função autor, ou seja, ver de que maneira se formou e funcionou este conceito.

O que Foucault procura fazer é definir seu objeto de estudo, enfatizando aspectos que ultrapassam a individualidade singular do autor. Ele não procura definir ou especificar um conceito abstrato e subjetivo do autor considerado em sua individualidade, mas em precisar o contexto no qual o sujeito atua e é apreendido pelos demais sujeitos. Assim, interessam-lhe as fundações e retomadas da materialidade do conceito de autor (suas funções), independente de qual seja ele. De modo similar, Frohmann, ao ser convidado a proferir a palestra de abertura do VII Encontro Nacional de Pesquisa em Ciência da Informação, ocorrido em Marília em novembro de 2006, que teve como tema "O caráter social, material e público da informação na contemporaneidade", procurou libertar-se de um conceito restritivo de indivíduo, prejudicial, em sua opinião, aos estudos no campo da ciência da informação.

Frohmann (2006, p 1-2), durante sua exposição, argumentou contra um conceito de informação subjetivo e abstrato, "mal equiparado para dirigir os conceitos centrais desta conferência", afirmando que "o foco em um conceito de informação como um significado imaterial presente à mente humana tem o efeito de limitar estudos dos efeitos de regimes de informação a investigações de mudanças na consciência dos indivíduos". Assim, o autor defendeu que "os indivíduos geralmente não são os agentes principais dos processos de interesse de estudos dos aspectos de informação culturais, econômicos, políticos, públi- 
cos e sociais", concluindo que "[a] materialidade é o mais importante dos três principais conceitos do tema da conferência, pois muito do caráter público e social da informação depende dela".

Este artigo procura desenvolver essa perspectiva de Frohmann. Defende-se que a Ciência da Informação encontrou sua expressão máxima do individualismo quando adotou uma orientação cognitivista, parcialmente como desdobramento da valorização do físico e sistêmico em seus anos fundadores. Por sua vez, a relativa ênfase no indivíduo representado cognitivamente desdobrou-se em uma necessidade de incorporação de dimensões diversas, como a sociológica, situacional, política, filosófica, lingüística, emocional, cultural, histórica e epistemológica. As tendências atuais apontam para a premência de uma abordagem holística, que efetivamente integre o material e o social. Assim, em consonância com as propensões e deslocamentos das Ciências Sociais, destacamse a emergência do neopragmatismo, dos novos estudos da linguagem, do construtivismo e suas repercussões no campo. A análise de domínio é considerada uma teoria representativa das inclinações contemporâneas, e por isso são expostos seus fundamentos. Os conceitos e a metodologia de Foucault são admitidos como um meio eficiente de construção de temas integrados a serem objetos de estudos no campo. Ainda, reconhecendo a tensão em que a virtualidade coloca a materialidade documental, efetuam-se alguns comentários sobre suas implicações para o argumento defendido no artigo.

\section{A VALORIZAÇÃO DO FísICO E SISTÊMICO NOS ANOS DE FUNDAÇÃO DA CIÊNCIA DA INFORMAÇÃO}

Em seus anos iniciais, a Ciência da Informação realçava o sistema e a fisicidade, herdeira de uma concepção material e quantitativa do objeto informação. Essa orientação depreende-se, por exemplo, da definição consagrada de Ciência da Informação por Borko (1968), com o destaque para os aspectos físicos da informação, como sua categorização, as forças que controlam seu fluxo e as técnicas de seu processamento, para otimização de seu armazenamento, recuperação e disseminação. Ocorreu uma influência direta da teoria da informação de Shannon e Weaver e da cibernética de Norbert Wiener. Havia também uma conexão com o esquema simplificador fonte-canal-receptor (CAPUR$\mathrm{RO}, 2003 \mathrm{~b}$ ), metafórico de uma entidade física ou energética efetivamente transmitida de uma fonte ao destinatário final.

$\mathrm{Na}$ teoria da informação (ou teoria matemática da comunicação) as mensagens ou sinais são transmitidos, e a informação é quantificada como uma medida de um repertório de signos colocados à 
disposição e escolhidos pelo emissor, que devem, necessariamente, ser (re)conhecidos pelo receptor. O sentido da informação é desconsiderado para o problema de engenharia delimitado, como destacado por Shannon (1948, p. 1):

(...) esses aspectos semânticos da comunicação são irrelevantes para o problema de engenharia. $\mathrm{O}$ aspecto significativo é que a mensagem é selecionada de um conjunto de possíveis mensagens. (...) Se o número de mensagens no conjunto é finito, então esse número ou qualquer função monotônica desse número podem ser considerados uma medida da informação produzida.

A informação é vista como uma função de probabilidade associada ao ruído no canal e aumenta a incerteza, que é reduzida pela mensagem. A entropia está ligada a essa probabilidade de escolha, à imprevisibilidade e à desorganização. A redundância é a repetição utilizada para garantir o perfeito entendimento. Desse modo, o objetivo é o estudo da comunicação de informação através de canais mecânicos, medindo-se a quantidade de informação passível de transmissão e evitando-se as distorções possíveis de ocorrer na propagação (ARAÚJO, 2003).

A teoria da informação, ao definir um modelo de fenômeno comunicativo, teve profunda repercussão nos estudos de comunicação de massa nas décadas de 1920 a 1950 e nas décadas iniciais de construção do campo da Ciência da Informação.
As experiências realizadas pelo Cranfield Institute of Technology, em 1957, estão fortemente relacionadas com essa concepção mecanicista da informação. Elas consistiam em criar um banco de informações bibliográficas (a coleção de teste), idealizar um conjunto de questões que possibilitassem a consulta ao banco e, com base em julgamentos efetuados por especialistas humanos, determinar a relevância de cada documento para cada questão. Assim, a relevância é concebida como uma relação entre documento e questão, abstraídos os demais fatores intervenientes. $O$ sucesso do processo de recuperação era, então, medido pelas relações entre documentos relevantes ou não, e documentos recuperados ou não, com ênfase nos aspectos de revocação, precisão e medidas quantificadas.

Os princípios dessas abordagens físicas subsistem. Atualmente, as medidas utilizadas para a avaliação quantitativa de sistemas de recuperação de informação não são muito diferentes. Tome-se o exemplo da Text REtrieval Conference (TREC) que tem o propósito de apoiar as pesquisas da comunidade de recuperação da informação, provendo a infra-estrutura necessária para a avaliação em larga escala de metodologias de recuperação de documentos textuais. Uma coleção de referência contém um conjunto de documentos, de tópicos (questões) e um conjunto 
correspondente de julgamentos de relevância (respostas corretas). Os julgamentos, dado o grande número de documentos, são construídos em um sistema de pool, consolidando o resultado de vários algoritmos (BAEZA-YATES; RIBEIRONETO, 1999).

\section{A HIPERVALORIZAÇÃO DO INDIVI-} DUALISMO MENTAL: O COGNITIVISMO

A partir da década de 1970 , algumas das direções mais produtivas dos estudos informacionais resultaram da adoção de uma perspectiva cognitivista. As expressões mais significativas do cognitivismo são os Estados Anômalos do Conhecimento de Belkin et al. (1982a, 1982b) e o mentalismo de Brookes (1980).

A visão de De Mey (1980, p. 48), na qual o processamento da informação desempenhado pelo sistema simula o processamento mental que o indivíduo realiza para entender o mundo, amplamente difundida e aceita por muitos autores de abordagens cognitivistas, exemplifica essa perspectiva: "[...] qualquer processamento de informação, perceptual ou simbólico, é mediado por um sistema de categorias ou conceitos que, para o dispositivo de processamento da informação, constituem o modelo de seu mundo."

Brookes formalizou seu conceito de informação baseado no conhecimento objetivo (conhecimento inteligível do mundo
3) desenvolvido por Popper (2000). Para ele, o conhecimento "... [é] uma estrutura de conceitos ligados por suas relações e informação [é] como uma pequena parte dessa estrutura" (BROOKES, 1980, p.131). A estrutura de conhecimento, que pode ser tanto subjetiva quanto objetiva, é transformada pela informação. Tal mudança pode ser expressa pela conhecida equação $\mathrm{K}[\mathrm{S}]$ $+\Delta \mathrm{l}=\mathrm{K}[\mathrm{S}+\Delta \mathrm{S}]$, na qual a estrutura de conhecimento $\mathrm{K}[\mathrm{S}$ ] é modificada para um novo estado $K[S+\Delta S$ ] pela informação $\Delta \mathrm{l}$, e $\Delta S$ indica o efeito da mudança. Conhecer é compreendido como um ato de interpretação ou assimilação da informação pelas estruturas mentais do indivíduo que percebe o meio durante uma interação. A produção do conhecimento se dá, então, pela reconstrução das estruturas mentais do indivíduo através da sua competência cognitiva, ou seja, pela modificação em seu estoque mental de conhecimento. Brookes (1980, p.131) expressou o ponto da seguinte forma: "[...] a absorção da informação em uma estrutura de conhecimento pode causar não apenas um acréscimo, mas algum ajuste na estrutura, bem como uma mudança nas relações entre dois ou mais conceitos já admitidos". Em suma, o indivíduo cria as estruturas de conhecimento e modelos mentais por meio da experiência e observação.

Com base nos pressupostos e assunções cognitivistas, Belkin et al. (1982a, 
1982b) idealizaram um modelo de recuperação de informação. A natureza do estado do conhecimento do usuário é considerada um fenômeno básico para a compreensão do processo de recuperação da informação. O usuário utiliza os sistemas de recuperação ao reconhecer uma anomalia ou um estado de conhecimento inadequado ou incoerente com relação a algum assunto ou problema, denominado estado anômalo do conhecimento (anomalous state of knowledge). Embora o usuário possa identificar o estado anômalo, ele não pode especificar o que é necessário para transpor o gap cognitivo, que foi exatamente o que o direcionou ao sistema. No entanto, embora não especificáveis, as necessidades de informação podem ser indiretamente esclarecidas através do relato da situação problemática experienciada pelo usuário.

Assim, as narrativas de problemas efetuadas pelos usuários são utilizadas pelo sistema de informação para recuperar, de um corpus de textos, um texto apropriado para resolver a anomalia. $O$ documento recuperado é visto como a representação de um estado coerente de conhecimento, enquanto que a pergunta ou texto relacionado com a necessidade de informação é a representação de um estado de conhecimento inadequado. A informação, então, se constitui na relação entre um corpus de textos disponíveis e um outro texto que expressaria um estado de conhecimento anômalo.

Para cada tipo de estado anômalo de conhecimento bastaria então especificar diferentes mecanismos e estratégias de recuperação da informação. O sistema constrói uma representação do conhecimento do usuário através de redes de associações entre palavras identificadas nas declarações narrativas do problema, examina essa estrutura, interpreta as características estruturais das representações para determinar os estados anômalos do conhecimento, e pesquisa as descrições de documentos estruturados com o objetivo de solucionar a anomalia. O usuário, então, avalia os documentos recuperados e essa avaliação é utilizada, pelo sistema, para determinar as adequadas modificações nas representações das necessidades do usuário, assim como a troca da estratégia para a definição das características significativas do mecanismo de busca adotado. O componente interativo é um aspecto crítico do sistema. Cada ciclo do processo de recuperação da informação depende da avaliação realizada pelo usuário dos ciclos anteriores, tendo em vista que a anomalia e a percepção do indivíduo com relação ao problema são modificadas a cada interação com o sistema. Em tese, o indivíduo cria as estruturas de conhecimento e modelos mentais por meio de sua história e relações sociais. 
Vê-se que a perspectiva cognitivista de Belkin e Brookes relaciona-se mais com as abordagens sistêmicas e físicas do que parece a princípio, haja vista a criação de um "objeto mental". A informação-coisa é agora concebida como uma imagem cerebral. Surgem inúmeras referências na literatura do campo a Popper, com seu terceiro mundo dos objetos inteligíveis (formulações lingüísticas compartilháveis, teorias, modelos e postulados de conhecimento sobre o mundo) ou à teoria platônica das idéias autônomas, como ocorre em Miranda (2002).

Também passa a ser incorporada na literatura do campo, com maior intensidade, a idéia de conhecimento. A transmissão e o processamento da informação possibilitariam o aprimoramento das estruturas de conhecimento do usuário individual. Outra idéia mais fortemente explorada é a de representação. O mundo externo seria representado mentalmente pelo usuário através de uma série de imagens e os sistemas de recuperação tenderiam a efetuar uma junção das estruturas mentais do construtor das bases de dados e das estruturas do usuário. Cabe observar que a concepção de best-match perdura. A noção sistêmica de relevância pressupõe a adequação a priori de um documento à questão proposta. Do ponto de vista cognitivista, há um documento que provocará a adequada reestruturação das estruturas mentais individuais, mesmo que para isso intervenham a observação, a experiência do usuário, sua história e relações sociais.

\section{A PREMÊNCIA DAS ABORDAGENS HOLÍSTICAS}

Um ataque radical ao ponto de vista cognitivista na Ciência da Informação partiu de Frohmann (1992), que efetuou uma análise do discurso mentalista. Para o autor, (a) ocorre um "imperialismo teórico", já que o cognitivismo almejaria unificar $o$ campo científico com base no conceito centralizador de imagens, em despeito das forças sociais; (b) há reificação, já que conceitos-chave como imagens, quadro, estrutura de conhecimento, modelos do mundo, constroem um mundo objetivo de figuras estáveis facilmente gerenciável; (c) as representações simplificadas possibilitam um processamento interno, similar ao computacional; (d) o campo social é apagado e reconstruído em um individualismo exacerbado; (e) o conhecimento é equiparado a suas simples representações; (f) o profissional da informação é colocado artificialmente em uma posição de onisciência em detrimento do usuário. Assim, opera-se uma razão instrumental, que prioriza a eficácia, a padronização e a obtenção de efeitos, em função de um discurso de transformação da informação em commodity, afinado com a economia pós-moderna de mercado. 
Capurro (1992, 2003a) percebe a emergência de um "paradigma social" na Ciência da Informação em seguida ao mentalismo cognitivista. Em sua concepção, partiu-se de abordagens puramente cognitivistas (Brookes e Belkin) para tendências que, gradativamente, levavam em conta os fatores sociais no cognitivismo (Ingwersen, por exemplo). Ao nosso ver, o que o "paradigma social" sinaliza são abordagens múltiplas que tendem a incorporar, de diversos modos e intensidades, dimensões anteriormente menos consideradas (sociológica, situacional, política, cultural, filosófica, lingüística, emocional, histórica, epistemológica), em consonância com os percursos das Ciências Sociais, e que cada vez mais atentam para a premência da integração das diferentes abordagens, tendendo a uma visão holística. Essa integração tende a realizar-se na própria construção do objeto de estudo, e não somente na justaposição de diferentes domínios e na admissão de que um deles influencie o outro (como em Belkin, por exemplo, ao admitir que interações sociais influenciam o modo pelo qual o indivíduo altera seus modelos mentais). Mesmo enumerar tantas abordagens é inviável em um espaço restrito e foge ao escopo deste artigo. Entretanto, pode ser útil apontar algumas delas e suas ligações com as Ciências Sociais, eventualmente distinguir algumas emblemáticas mudanças e acréscimos, e chamar a atenção para alguns métodos cujo uso generaliza-se no campo.

A teoria dos ambientes informacionais de Taylor $(1982,1991)$ analisa o ambiente de uso da informação, considerando os determinantes situacionais dos grupos de trabalho, das classes de problemas, dos ambientes de trabalho e das soluções de problemas. Na consideração do ambiente de trabalho são valorizadas suas características físicas e sociais. Os pressupostos e atitudes comuns que influenciam as necessidades de informações são úteis para identificar os grupos de usuários de informação. Os problemas mais freqüentes são diagnosticados e os modos de solução habitualmente esperados pelos usuários são investigados, um ponto que revela um distanciamento da perspectiva tradicional dos sistemas de recuperação de informação, que procuram soluções a partir do problema delimitado (best-match).

Bates (2005) ressaltou a influência nos trabalhos de Kuhlthau e Dervin da abordagem construtivista, oriunda da educação e sociologia, na qual os indivíduos são vistos como ativamente construindo e entendendo seus mundos, fortemente influenciados pelo mundo social no qual operam. O processo de busca de informação de Kuhlthau (2005) é uma construção efetuada pelo sujeito em fases a que correspondem ações, pensamentos e emoções. A estrutura não é linear, já que o sujeito 
experiencia emoções conflitantes que podem extinguir-se e retornar no processo, como a ansiedade ligada à incerteza percebida.

O Sense-Making de Brenda Dervin (1983) é uma ferramenta conceitual e metodológica para a compreensão de como criamos sentido a partir de informação. A teoria enfatiza as situações vividas pelos usuários, em um espaço-tempo composto de suas histórias, experiências e horizontes, os gaps enfrentados (as questões e as confusões e angústias derivadas) e as construções de pontes para a suplantação dos gaps, que podem ser idéias, pensamentos, atitudes, intuições, cognições, etc, e que constituem um processo comunicacional. Tidline (2005, p. 114) viu um longo percurso na metodologia desde que surgiu na década de 80 , e identificou uma preocupação recente com o contexto, com o Sense-Making coletivo e com a verbalização (verbing) (DERVIN, 1993), o que possibilita "transcender a simples classificação e alcançar um entendimento holístico da atividade de informação".

Weick (1995) desenvolveu sua teoria de sensemaking, que procura explicar como, ao constituir nossas identidades, criamos o ambiente atentando para seus aspectos salientes em um processo contínuo, social e retrospectivo, e fazendo uso intenso da linguagem para construir nossas verdades ou justificar nossas ações. 0 sensemaking de Weick é considerado por Choo (1998) como uma das utilizações estratégicas da informação, e relacionado com necessidades e processos de busca de informação específicos.

As próprias abordagens cognitivas tornaram-se mais integrativas, procurando destacar os aspectos situacionais e sociais. Mesmo Belkin, no começo da década de 90, embora ainda mantendo-se fiel às suas premissas cognitivistas, sinalizou a tendência de discernir dois níveis de análise dos processos cognitivos, em sua relação com a informação: um micro-nível, de análise de um ato pontual de cognição, e um macro-nível, de identificação das metas e objetivos do usuário e de um "domínio da representação" (BELKIN, 1990). Há vários outros exemplos. A cognição social de Bandura enfatiza o conceito de selfefficacy, que estipula que as pessoas geram seus pensamentos, afetos e comportamentos, que afetam a sua própria geração e influenciam as ações das pessoas, o esforço envolvido, o comprometimento e a resistência ao fracasso. Assume-se que os fatores cognitivos, comportamentais e ambientais atuam de modo intrínseco e que há sempre múltiplos níveis de metas geradas. Esses pressupostos são úteis para o estudo do comportamento de busca de informação (MIWA, 2005). A teoria da autoridade cognitiva pressupõe que a autoridade é social e interativamente determinada; 
esse posicionamento está próximo à noção de relevância na recuperação de informação (RIEH, 2005). A teoria do posicionamento social argumenta que constantemente as pessoas posicionam-se entre si por meio de práticas discursivas e oferece uma base para um estudo das presunções estereotipadas em encontros com profissionais de informação (GIVEN, 2005).

Alguns métodos, cuja utilização generalizam-se atualmente na comunidade brasileira de Ciência da Informação, evidenciam perfeitamente uma perspectiva que suplanta o tratamento do sujeito em sua individualidade. $O$ discurso do sujeito coletivo - DSC (ALMEIDA, 2005) é um método científico, baseado na teoria das representações e em idéias de Peirce, que procura construir um discurso coletivo em primeira pessoa, resumindo o exposto em expressões-chave e considerando as idéias centrais (ancoragens) nos vários discursos coletados. A análise de redes sociais (MARTELETO; TOMAÉL, 2005) é um método de base quantitativa que considera como unidades básicas de análise as interações entre os atores e seus papéis, elos e posições. São exploradas as dimensões informacionais e comunicacionais, lingüísticas e discursivas, e relativas à produção de sentido na análise (MARTELETO, 2000).

\section{PRAGMATISMO, LINGUAGEM E CONSTRUTIVISMO}

O pragmatismo e a filosofia da linguagem tiveram papel preponderante na diversificação das abordagens no campo da Ciência da Informação. Pogrebinschi (2005), analisando os trabalhos fundadores de Peirce, William James e Dewey, baseou a matriz filosófica do pragmatismo em torno de três núcleos: (1) o antifundacionalismo, que consiste em uma rejeição a qualquer espécie de entidade metafísica ou categoria apriorística, implicando uma crítica constante; (2) o conseqüencialismo ou instrumentalismo, relacionado ao julgamento de proposições com base em um teste conseqüencialista e a uma reavaliação da verdade; (3) o contextualismo, com a valorização da experiência, da prática e dos fatos, insistindo em uma investigação compartilhada para gerar significados e idéias convergentes. Essas características pressupõem um afastamento da metafísica, a rejeição do nominalismo e uma proximidade com o realismo. Defende-se que o valor de verdade é um valor prático das ações humanas. A função do pensamento é produzir hábitos de ação, que dariam sentido às coisas. Os conceitos de ação e comunicação, já presentes no pragmatismo, foram fundamentais para um posterior desenvolvimento da teoria social, como Pogrebinschi procura mostrar. 
Na década de 1930, o pragmatismo perdeu terreno para a filosofia analítica, embora uma de suas ramificações tenha sobrevivido, o interacionismo simbólico, desenvolvido pelos discípulos de Mead na escola de Chicago. O renascimento do pragmatismo, ou neopragmatismo, nas últimas duas décadas do século $X X$, foi simultâneo a uma "orientação das condições e pressupostos da linguagem como contexto e meio da investigação filosófica" (POGREBINSCHI, 2005, p. 103). Assim, aparecem relacionadas a "virada pragmática" e a "virada lingüística". A nova ênfase na linguagem passa por uma retomada $e$ reorientação de sua abordagem lógica e analítica pelo Círculo de Viena. Atenta-se para os modos de uso e jogos da linguagem, partes de diferentes modos de vida (Wittgenstein) ou para os componentes locucionários (dizer alguma coisa), ilocucionários (diversos significados da coisa dita) e perlocucionário (efeitos da coisa dita) dos atos de fala (Austin). Embora com ressalvas, nota-se a influência do pragmatismo e das novas abordagens dos estudos da linguagem na pragmática universal de Habermas, uma filosofia voltada para a interação social, a linguagem e a intersubjetividade.

No campo da Ciência da Informação, Capurro (1992) enquadrou como integrantes da "virada pragmática" na década de 80 a abordagem comportamental de Roberts do "homem informacional" ou a teoria das "ações informacionais" de Wersig (WERSIG; WINDEL, 1985). Encarar a informação como uma ação implica supor que os diversos atores estão inseridos em situações problemáticas e que é a intencionalidade do ator que faz uma ação significativa. Cada sistema de agenciamento da ação tem diferentes potencialidades ou disposições que caracterizam diversos espaços de realização da ação. As repercussões do pragmatismo também estão presentes nos pontos de vista da hermenêutica e da retórica (CAPURRO, 1992, 2000), que só admitem o conhecimento em um horizonte de pré-compreensão em um mundo comum, cujo partilhamento temático e situacional constitui informação, e que destacam o papel da interpretação, dada justamente a impossibilidade de diferenciar informação de desinformação.

Ainda, o deslocamento nos estudos da linguagem é que possibilitaram as reorientações nos estudos de origem cognitiva. Assim, é a linguagem que Talja, Tuominen e Savolainen (2005) utilizam para diferenciar o construtivismo social do construcionismo. A primeira categoria não institui que as estruturas de conhecimento e os modelos mentais individuais são influenciados pela história de interações sociais, como o construtivismo de base cognitiva, mas julga que o conhecimento é social na origem; o indivíduo vivendo em um mundo física, so- 
cial e subjetivamente construído e havendo uma constituição recíproca das estruturas de conhecimento do indivíduo e do ambiente sócio-cultural. Já a segunda categoria, a do construcionismo, propugna que o conhecimento e a identidade são construídos em discursos que categorizam o mundo e colocam os fenômenos em perspectiva.

Teorias classificadas como sócioconstrutivistas ou construcionistas têm repercutido nos estudos de práticas informacionais, tesauros, sistemas de classificação e organização do conhecimento em diferentes domínios, assim como na análise de discursos e dos comportamentos de informação de profissionais e nos projetos de bibliotecas digitais (TALJA, TUOMINEN; SAVOLAINEN, 2005). Além disso, do ponto de vista dessas teorias, o termo "prática informacional" é preferível ao "comportamento informacional", pois o primeiro assume que os processos de busca e uso de informação são constituídos dialógica e socialmente, antes que baseados em motivos e idéias individuais (TUOMINEN, TALJA; SAVOLAINEN, 2005). Por fim, a ênfase na linguagem nas formações sociais nos conduz às teorias precursoras de Foucault.

\section{FOUCAULT: POSSÍVEIS PONTES ENTRE O MATERIAL E O SOCIAL}

Até o momento, temos procurado mostrar como as abordagens mais recen- tes têm enfocado o objeto de análise dos estudos informacionais integrando suas diversas dimensões em um escopo supraindividual. Mas como ficam os estudos que enfatizam os aspectos físicos e sistêmicos da informação? Essa dimensão tem sido constantemente valorizada (ou mesmo resgatada) em muitos trabalhos. É o que faz Buckland (1991), realçando a informação-coisa sem a exclusão de suas dimensões processuais e de conhecimento. De maneira semelhante, destaca-se o esforço consubstanciado no denominado "Trilema de Capurro" (CAPURRO; FLEISSNER; HOFKIRCHNER, 1999; CAPURRO, 2003a), que busca unificar o conceito de informação explorando as dimensões análogas, equívocas e unívocas das diversas definições pré-existentes, materiais, cognitivas ou sociais.

A integração entre o material e a sociedade é estabelecida em Foucault praticamente como um método. $\mathrm{O}$ autor adotou uma abordagem de análise de discurso que constantemente é percebida como construcionista. O conhecimento é construído em um sistema de dispersão, múltiplo e refletor das inúmeras forças antagônicas, e não relativamente estável como na concepção de estruturas mentais individuais. Quando se percebe uma ordem entre diversos elementos, sejam eles conceitos ou objetos, pode-se discernir uma formação discursiva. Para Foucault, o conceito é real 
e concreto, como a disposição de livros nas estantes de uma biblioteca. O ponto é que essa formação está intrinsecamente relacionada às práticas sociais na medida em que resulta delas, e também as origina: os contatos, interações e percursos efetuados na biblioteca são dependentes da materialidade de sua organização.

Um conceito central para a análise das formações discursivas é a enunciação, elemento que aparece no contexto de uma formação discursiva e é considerado material pelo autor. Enunciações não se reportam a conceitos ou idéias na mente de uma pessoa. Não são consideradas pelo que significam ou representam, mas pela sua própria existência. Uma enunciação tem uma materialidade (massa, inércia, resistência) que resulta do grau de seu engajamento institucional. Enunciações são ligadas pelas rotinas institucionalizadas. A análise das enunciações constitui uma perspectiva para a descrição das condições nas quais os textos aparecem (RADFORD; RADFORD, 2005). Para Frohmann (2006), essa análise é um recurso para abordar a materialização da informação por meio da documentação. Note-se que Foucault também destaca as conseqüências do aparecimento das enunciações.

A enunciação é material, mas não objetiva. Foucault (1999) esclarece que não se trata de compreender o conhecimento objetivo, a idéia, o conceito, essa estabilização da realidade na qual o homem pode reconhecer-se e a ciência delinear-se. Trata-se de evidenciar o campo epistemológico, a epistémê, quando os conhecimentos são abstraídos de seus valores racionais e de suas formas objetivas, e manifestam-se em sua pesada positividade, evidenciando as suas condições de possibilidades. $O$ que se revela é o espaço do saber, as trajetórias desveladoras das coisas e objetos ou os percursos esclarecedores dos documentos nas instituições, as configurações propiciadoras e, ao mesmo tempo, propiciadas pelo material. Trata-se, enfim, de uma arqueologia.

Conforme Ferreira (1999), a arqueologia é um método para alcançar a inteligibilidade da discursividade local. Já a genealogia, um método que demarca a gênese de um saber sobre a anomalia e torna visíveis as técnicas empregadas, ativa ou liberta saberes locais, desqualificados e não legitimados, do jugo de uma instância teórica unitária que quer hierarquizá-los e ordená-los em nome de uma ciência controlada por poucos. Pensa-se ser válido dizer que a genealogia e a arqueologia pressupõem o reconhecimento dos dispositivos, redes heterogêneas de discursos, decisões, leis, enunciações científicas, medidas administrativas, proposições morais ou filosóficas, em suma de todo o dito, mas também do não dito. Essas redes respon- 
dem à urgência de determinada época, sendo, assim, preenchidas de distintas maneiras, adequadas à estratégia da época.

\section{A ANÁLISE DE DOMÍNIO}

Tendo em vista as relações históricas da Ciência da Informação com a documentação e biblioteconomia, é esperado que as teorias do campo enfatizem os aspectos materiais e documentais presentes na prática cotidiana. Essa, sem dúvida, é uma das preocupações da teoria denominada análise de domínio criada por Hjørland e Albrechtsen (1995). Essa teoria preceitua que a mais proveitosa atitude para a Ciência da Informação é estudar os domínios do conhecimento como comunidades de discurso ou pensamento, que são partes da divisão do trabalho em uma sociedade. Trata-se de uma abordagem social-epistemológica, funcionalista e realista, que procura transcender as percepções individualistas e subjetivas dos usuários para fundamentar seus princípios e metodologia.

Adquire especial importância o estudo das ligações dos discursos, das áreas do conhecimento e dos documentos sob as diversas perspectivas ou pontos de acesso das comunidades de usuários. Procura-se uma integração da perspectiva individualista $\mathrm{e}$ isolacionista das abordagens cognitivistas com o contexto social das comunidades. Os conceitos de informação só têm sentido em relação a um pressuposto conhecido e compartilhado entre os diversos membros da comunidade, e é com essa argumentação que Capurro (2003a) procura destacar os pontos em comum da análise de domínio com a hermenêutica e o conceito de pré-compreensão.

Um domínio pode ser uma disciplina científica, um campo científico ou uma comunidade discursiva relacionada a um partido político, à religião, ao comércio, dentre outros. Domínios científicos não se distinguem dos laicos para o fim de análise. Os domínios são normalmente definidos por teorias ontológicas (seus objetos). As dimensões epistemológicas dos domínios dizem respeito aos diferentes modos de conhecimento. As dimensões sociológicas, centrais na análise de domínio, referem-se aos diferentes grupos de pessoas estudando os diversos campos de conhecimento. Hjørland (2004, p. 6) assim resumiu o argumento:

(...) todas as três dimensões são importantes na análise de domínio. A análise de domínio explora relações ontológicas, isto é, relações genéricas em tesauros e sistemas de classificação. Também estuda grupos sociais como cientistas, profissionais, estudantes ou crianças. Finalmente, estuda epistemologias, paradigmas, tradições, teorias, o que é importante porque pessoas tendem a se organizar de acordo com suas visões.

A análise de domínio adota um ponto de vista sócio-cognitivo (HJøRLAND, 2004), que valoriza os papéis da cultura e 
da sociedade na cognição. Em detrimento das representações simbólicas, as pesquisas em semântica e pragmática são enfatizadas, agora considerando as ações como entidades básicas na análise. Em suma, a ênfase é deslocada para a internalização de signos e símbolos socialmente produzidos e no modo pelo qual os processos cognitivos são mediados por significados construídos cultural, histórica e socialmente.

Filosoficamente, é adotada uma visão pragmático-realista, o que implica distinção prática entre conhecimento subjetivo e objetivo, este norteando e configurando as possibilidades do primeiro, assim como um modo de entendimento do conceito de relevância na Ciência da Informação, que está orientado a objetivos e propósitos dentro de determinada domínio e baseado em argumentos próprios ao contexto.

Hjørland (2002) descreveu onze abordagens, entre tradicionais e inovativas, para a análise de domínio na Ciência da Informação. As abordagens mais tradicionais são, entre outras, a criação de guias de literatura para áreas específicas, a produção de classificações especializadas e tesauros, estudos bibliométricos e pesquisas em indexação e recuperação de informação. Essas abordagens tradicionais são mediadas por estudos inovadores de linguagem, de gênero, históricos, epistemológicos e críticos nos diversos domínios, para a determinação de suas especificidades. O autor espera que esses estudos, utilizando uma combinação dessas abordagens, reforcem a identidade da Ciência da Informação, aproximem teoria e prática e promovam um exercício de interdisciplinaridade.

Considerados seus pressupostos, é de se esperar que a teoria tenha muitas aplicações práticas. López-Huertas (2006) utilizou a teoria para a análise da terminologia de estudos de gêneros e construção de tesauros. Talja (2005) empregou a teoria para estudo das práticas informacionais de acadêmicos, percebendo diferenças significativas no domínio em relação às conhecidas fases de pesquisa do modelo de Ellis, que pretendem identificar similaridades nos padrões de busca de informação em diferentes domínios.

\section{AS TENSÕES GERADAS PELO VIRTUAL}

Em sua exposição, Frohmann (2006) sustentou que a informação não é materializada apenas por um meio institucional, mas também por meios tecnológicos, constituindo os enunciados digitais. A questão que se prenuncia é em que medida a virtualização dos objetos torna necessária uma reformulação do conceito de materialidade em Foucault.

Lévy (2005) argumentou que os objetos são sustentadores do virtual. Eles são 
mediadores da inteligência e implicam um contrato ou convenção (o autor os compara com uma bola de futebol no estádio). São elos de ligação, conectam os indivíduos e constituem os sujeitos (social, cognitivo e prático). Em alguns pontos, sua análise aproxima-se do conceito do material em Foucault. Claro, a questão admite várias interpretações e, novamente, foge ao escopo do artigo. No entanto, cabem duas observações.

A primeira é que, como se procurou demonstrar, a "abstração" dos objetos, principalmente em contextos de sua virtualização ou digitalização, desemboca facilmente na utilização dos mesmos pressupostos de abordagens estritamente fisicistas ou cognitivistas (na medida em que um objeto popperiano do $3^{\circ}$ mundo inteligível poderia ser manipulado ou processado tão facilmente, ou sob pressupostos bastante limitados e limitadores, como um objeto físico).

A segunda é que, talvez, mais fácil que focar a discussão propriamente nos objetos digitais, seja perceber que a instituição sempre permanece, mesmo que provavelmente alterada, no meio virtual. A automatização não descarta a intencionalidade humana (mesmo que se admita aqui um ainda).

\section{A CONSTRUÇÃO HOLÍSTICA DO SUJEITO E DO OBJETO DE ESTUDO}

A análise efetuada dá margens a comentários e defesa de alguns pontos de vista. Diz-se comumente que, após o período de fundação, a Ciência da Informação deslocou-se em direção ao usuário. Essa afirmação é matizada quando os movimentos em torno do conceito de usuário são discernidos: sua pré-concepção modelar nas abordagens sistêmicas e fisicistas iniciais, a aproximação de um usuário considerado em suas estruturas mentais nas abordagens cognitivistas e novamente um afastamento do usuário individualizado nas abordagens contemporâneas mais integradas e pragmáticas para valorizar o "usuário social" criado em uma rede de relacionamentos sociais multidimensionais em tempo e espaço próprios.

De forma semelhante, esclarece-se em alguns pontos a relação da Ciência da Informação com a ciência social. Nascida de uma perspectiva quantitativa e funcionalista, a Ciência da Informação começa a discutir na década de 1970 seu próprio estatuto de ciência social. No entanto, como destacou Araújo (2003), essa discussão inicial "parecia mais delinear uma subárea dentro da ciência da informação (a área da 'informação social') do que, propriamente, reformular a forma como a ciência da informação, como um todo, compreende e estuda seu objeto de estudo". O autor ar- 
gumentou que os pressupostos da Ciência da Informação só seriam revistos com a aproximação aos enfoques sociais microssociológicos e interpretativos. Como procurou-se mostrar, não se trata de justaposições de dimensões de diversos matizes sociológicos, situacionais, históricos, e outros, mutuamente se influenciando, mas da construção integrada do objeto de estudo, única possibilidade de abordagens efetivamente holísticas. Para isso, consideraram-se importantes os avanços sociais de teorias neopragmáticas, dos novos estudos da linguagem e da mente, e das perspectivas construcionistas.

Exploraram-se alguns conceitos e teorias de Foucault, devido à sua ênfase na materialidade, tão cara ao nosso campo. Pelo mesmo motivo, delinearam-se os pressupostos da análise de domínio. Une as duas exposições a constatação de certas presunções e atitudes em relação aos temas de estudo. O foco não está exatamente em definir o objeto de estudo, seu comportamento ou suas características, mas antes, de maneira um pouco insubordinada, em indagar como o objeto é viabilizado, em quais jogos ele está envolvido, quais os percursos de sua materialidade, ou, nos termos foucaultianos que pretendem sintetizar a visão de história do autor, quais as condições de sua possibilidade.

A interdisciplinaridade, mais que uma proposição, surge como uma constatação ao se discorrer sobre algumas teorias do campo, suas aplicações práticas ou metodologias cuja utilização cresce. Se, em última instância, a Ciência da Informação remete-se ao indivíduo, não deve fazê-lo de maneira excessivamente direta, delimitando-o e limitando-o a priori. A construção holística e interdisciplinar (eventualmente transdisciplinar) de seu objeto de estudo é capaz de constituir o indivíduo em suas múltiplas dimensões, como um sujeito no mundo e entre documentos, talvez a única maneira viável de atingi-lo.

\section{REFERÊNCIAS}

ALMEIDA, C. C. Discurso do Sujeito Coletivo: reconstruindo a fala do "social". In: VALENTIM, M. L. P. (Org.) Métodos qualitativos de pesquisa em Ciência da Informação. São Paulo: Polis,2005. p. 59-79.

ARAÚJO, C. A. A pesquisa norteamericana. In: HOHLFELDT, A.; MARTINO, L. C.; FRANÇA, V. V. (Orgs.). Teorias da comunicação: conceitos, escolas e tendências. 3 ed. Petrópolis: Vozes, 2003.

BAEZA-YATES, R.; RIBEIRO-NETO, B. Modern Information Retrieval. New York: ACM Press, 1999.

BARTHES, Roland. A Morte do Autor. In: . O rumor da língua. São Paulo: Martins Fontes, 2004.

BATES, M. J. An Introduction to Metatheories, Theories, and Models, In: FISHER, K.E.; ERDELEZ, S.; McKECHNIE, L. Theories of Information Behaviour. Medford: Information Today, 2005. 
BELKIN, N.J. The cognitive viewpoint in information science. Journal of Information Science, v. 16, n. 1, p. 11-15, 1990.

BELKIN, N.J.; ODDY, R.N.; BROOKS, H.M. Ask for Information retrieval: Part I. Background and theory. Journal of Documentation, v. 38, n. 2, p. 61-71, 1982a.

ASK for information retrieval: Part II. Results of a design study. Journal of Documentation, v. 38, n. 3, p.145-164, $1982 b$.

BORKO, H. Information science: what is it? American Documentation, v. 19, n. 1, p. 35, jan., 1968.

BROOKES, B.C. The foundations of information science: Part I: Philosophical Aspects. Journal of Information Science, v. 2, p. 125-133, 1980.

BUCKLAND, M. Information as thing. Journal of the American Society for Information Science, v. 42, n. 5. p. 351-360, 1991.

CAPURRO, R. Epistemologia e Ciência da Informação. In: ENCONTRO NACIONAL DE PESQUISA EM CIÊNCIA DA INFORMAÇÃO - ENANCIB, V, Belo Horizonte, 2003. Anais... Belo Horizonte, 2003a.

Foundations of information science: review and perspectives. 2003b. Disponível em:

<http://www.capurro.de/tampere91.htm> Acesso em: 07 jul. 2006.

Hermeneutics and the phenomenon of information. In: MITCHAM, C. (Ed). Metaphysics, epistemology, and technology: research in philosophy and technology. v. 19, JAl/Elsevier Inc. p. 79-85, 2000. Disponível em:

<http://www.capurro.de/ny86.htm> Acesso em: 07 jul. 2006.

What is information science for? A philosophical reflection. In: VAKKARI, P.; CRONIN, B. (Eds.). Conceptions of Library and Information Science. London: Taylor Graham, p. 82-96, 1992.
CAPURRO, R.; FLEISSNER, P.; HOFKIRCHNER, W. Is a unified theory of information feasible? A Trialogue. In: HOFKIRCHNER, W. (Ed.): The Quest for a Unified Theory of Information. Proceedings of the Second International Conference on the Foundations of Information Science, $p$. 9-30, 1999. Disponível em: <http://www.capurro.de/trialog.htm> Acesso em: 07 jul. 2006.

CHOO, C. W. The knowing organizational: How organizations use information to construct meaning, create knowledge, and make decisions. New York: Oxford University Press, 1998.

DE MEY, M. The relevance of the cognitive paradigm for information science. In: HARBO, Ole; KAJBERG, (ed.): Theory and application of information research. London: Mansell, p. 48-61, 1980.

DERVIN, B. Verbing communication: Mandate for disciplinary invention. Journal of Communication, v. 43, n. 3, p. 45-54, 1993.

. Information as a user construct: the relevance of perceived information needs to synthesis and interpretation. Knowledge Structure and Use:implication for synthesis and interpretation. Philadelphia: Temple University, Press. p. 153-83, 1983.

FERREIRA, M. X. Michel Foucault e a ciência da informação: interações. Informare, v. 5, n, 2, p. 38- 46, 1999.

FOUCAULT, M. As palavras e as coisas: uma arqueologia das ciências humanas. 8. ed. São Paulo: Martins Fontes, 1999.

Vega, 1992.

O que é um autor? 2. ed. Lisboa:

FROHMANN, B. O caráter social, material e público da informação na contemporaneidade. In: ENCONTRO NACIONAL DE PESQUISA EM CIÊNCIA DA INFORMAÇÃO - ENANCIB, VII, Marília. Anais...

Marília, 2006. (CDRom) 
The power of images: a discourse analysis of the cognitive viewpoint. Journal of Documentation, v. 48, n .4, p. 365-386, 1992.

GIVEN, L. M. Social Positioning. In: FISHER, K.E.; ERDELEZ, S.; McKECHNIE, L. Theories of Information Behaviour. Medford: Information Today, 2005

HJØRLAND, B. Domain analysis in information science: eleven approaches traditional as well as innovative, Journal of Documentation, v. 58, n. 4, p. 422-462, 2002.

Domain analysis in information science. In: ENCYCLOPEDIA of Library and Information Science. New York: Marcel Dekker, p. 1-7, 2004. Disponível em: <http://www.dekker.com/servlet/product/DO I/101081EELIS1200249 90> Acesso em: 07 jul. 2006.

HJØRLAND, B.; ALBRECHTSEN, H. Toward A New Horizon in Information Science: Domain Analysis. Journal of the American Society for Information Science, v. 46, n. 6, p. 400-425, 1995.

KUHLTHAU, C. Kuhlthau's Information Search Process. In: FISHER, K.E.; ERDELEZ, S.; McKECHNIE, L. Theories of Information Behaviour. Medford: Information Today, 2005.

LÉVY, P. O que é o virtual? São Paulo: Ed. 34, 1996.

LÓPEZ-HUERTAS, M. J. Análisis del Dominio Interdisciplinar para la Representación y Organización del Conocimiento. In: GONZÁLEZ DE GÓMEZ, M. N.; ORRICO, E. G. D. Políticas de memória e informação: reflexos na organização do conhecimento. Natal: EDUFRN, 2006.

MARTELETO, R. M. Redes e configurações de comunicação e informação: construíndo um modelo interpretativo de análise para o estudo da questão do conhecimento na sociedade. Investigación Bibliotecológi- ca, México, v.14, n. 29. p. 69-94, jul./dic. 2000.

MARTELETO, R. M; TOMAÉL, M. I. A Metodologia de Análise de Redes Sociais (ARS). In: VALENTIM, M. L. P. (Org.) Métodos qualitativos de pesquisa em Ciência da Informação. São Paulo: Polis, 2005.

MIRANDA, A. A ciência da informação e a teoria do conhecimento objetivo: um relacionamento necessário. In: AQUINO, M. A (Org.). O campo da Ciência da Informação: gênese, conexões e especificidades. João Pessoa: Ed UFPB, 2002.

MIWA, M. Bandura's Social Cognition. In: FISHER, K.E.; ERDELEZ, S.; McKECHNIE, L. Theories of Information Behaviour. Medford: Information Today, 2005.

POGREBINSCHI, T. Pragmatismo: teoria social e política. Rio de Janeiro: Relume Dumará, 2005.

RADFORD, G. P.; RADFORD, M. L. Structuralism, post-structuralism, and the library: de Saussure and Foucault. Journal of Documentation, v. 61, n. 1, p. 60-78, 2005.

RIEH, S. Y. Cognitive Authority. In: FISHER, K.E.; ERDELEZ, S.; McKECHNIE, L. Theories of Information Behaviour. Medford: Information Today, 2005.

SHANNON, C. E. A mathematical theory of communication. The Bell System Technical Journal, v. 27, p. 379-423, 623-656, 1948.

TALJA, S. The Domain Analytic Approach to Scholars' Information Practices. In: FISHER, K.E.; ERDELEZ, S.; McKECHNIE, L. Theories of Information Behaviour. Medford: Information Today, 2005

TALJA, S.; TUOMINEN, K.; SAVOLAINEN, $R$. "Isms" in information science: constructivism, collectivism and constructionism. Journal of Documentation, v. 61, n. 1, p. 79-101, 2005. 
TAYLOR, R. S. Information use environment. In: DERVIN, B.; VOIGT, M.J. (Ed.). Progress in Communication Sciences, $v 10$. New Jersey: Norwood, 1991. p. 217-255,

. Value-added process in the informationa life cycle. Journal of the American Society for Information Science (JASIS), v. 33, n. 5, p. 341-346, 1982.

TIDLINE, T. J. Dervin's Sense-Making. In: FISHER, K.E.; ERDELEZ, S.; McKECHNIE, L. Theories of Information Behaviour. Medford, NJ: Information Today Inc, p. 113-117, 2005.

TUOMINEN, K; TALJA, S.; SAVOLAINEN, $R$. The social constructionist viewpoint on information practices. In: FISHER, K.E.; ERDELEZ, S.; McKECHNIE, L. Theories of Information Behaviour. Medford: Information Today, 2005.

WEICK, K. E. Sensemaking in Organizations. Thousand Oaks: Sage Publications, 1995.

WERSIG, G.; WINDEL, G. Information Science needs a theory of 'information action'. Social Science Information Studies, v. 5, p. 11-23, 1985.

Luiz Fernando de Barros Campos

Mestrando em Ciência da Informação (EClUFMG). Especialista em Gestão Estratégica da Informação (ECI-UFMG). Analista de Sistemas. Engenheiro Eletricista pela UFMG. Ifbcampos@gmail.com

\section{Ludmila Salomão Venâncio}

Mestranda em Ciência da Informação (EClUFMG). Especialista em Gestão Estratégica da Informação (ECI-UFMG). Tecnóloga em Informática salomao@eci.ufmg.br

\section{Title}

The object of study of Information Science: the death of the individual subject

\begin{abstract}
Argues that Information Science field achieved its most intense individualist expression when it adopted a cognitive orientation, partially as a development from the physical and systemic valorization in its initial years. Intends to show, through an epistemological exposition of metatheories, that the present trends point to the urgency of a holistic and interdisciplinary perspective, that effectively integrate the material and social aspects and assembles the sociological, situational, political, philosophical, linguistic, emotional, cultural, historical and epistemological dimensions. Thus, the emergence of the neopragmatism, the new studies on language and mind, the constructivism as well as theirs repercussions on the field are outlined. The domain analysis basis, considered exemplar for the argument defended, is exposed. Foucault's concepts and methodology are acknowledged as an effective mean to constitute integrated objects of study. Based on the defined scope, the implications of virtuality are commented, recognizing that it puts documental materiality in tension.
\end{abstract}

\section{Keywords}

Object of Study, Cognitivism, Neopragmatism, Language, Constructivism, Domain Analysis

\section{Título}

El objeto de estudio de la Ciencia de la Información: la muerte del individuo

\section{Resumen}

Se argumenta que el campo de la Ciencia de Información ha encontrado su máxima expresión del individualismo cuando adoptó una orientación cognitivista parcialmente como despliegue/desdoblamiento de la valoración de lo físico y sistémico en sus años fundadores. Se busca mostrar a través de una exposición epistemológica de metateorías, que las ten- 
dencias actuales apuntan la urgencia de un enfoque holístico e interdisciplinario, que de modo efectivo integre lo material y lo social e incluya dimensiones múltiples, como la sociológica, situacional, política, filosófica, lingüística, emocional, cultural, histórica y epistemológica. Por eso, se destaca el surgimiento del neopragmatismo, de los nuevos estudios del lenguaje y de la mente, del constructivismo y sus repercusiones en el campo. El análisis de dominio es considerado ejemplar del argumento defendido, y por eso se exponen sus fundamentos. Los conceptos y la metodología de Focault són admitidos como un medio efectivo de la constitución de objetos integrados. Además, en la amplitud delimitada, reconociéndose la tensión en que la virtualidad pone la materialidad documental, se efectuan algunos comentarios sobre sus implicaciones.

\section{Palabras Clave}

Objeto de estudio, Cognitivismo; Neopragmatismo; Lenguaje; Constructivismo; Análisis de Dominio.

Recebido em: 01.12.2006

Aceito em: 08.01.2007 